\title{
Scaling up community activism: the role of intermediaries in collective approaches to community energy
}

\author{
Caroline Bird* \\ University of Bristol \\ Jake Barnes \\ Bristol Energy Network and University of Sussex
}

\begin{abstract}
Summary
Intermediary organisations can play a significant role in the changing environment of UK energy, transcending the perceived divides between individual action, activism and top-down policy. This paper discusses a Bristol based action research project which, working with local community energy groups, explored the role of intermediary organisations not just in bringing together learning, providing support and aggregating impact but also in helping to shape stronger local energy action by connecting across and beyond existing activity in ways that put communities first. This approach enabled the development of the 'Bristol Community Strategy for Energy', which takes a different approach to the national 'Community Energy Strategy' which it preceded. We consider the roles of intermediary organisations in scaling up community activity: linking with policy and supporting shared action to accelerate community responses to energy concerns. We also draw on the underpinning theory before concluding with recommendations to reinforce the maturing and changing local energy landscape.
\end{abstract}

Keywords: Community energy, intermediary organisations, community energy strategy, scaling up, participatory methods.

\section{Introduction}

'Energy' in its current form is increasingly viewed as problematic, with our dependency on (big business) fossil fuels causing increasing inequalities and power relations which block change at all levels (Urry, 2014). There are concerns over security of supply, energy wastage and overuse, cost and inequality, and a lack of trust; all of which are being addressed both at a policy level and, increasingly, through local action. In the UK, a recent flourishing of community energy initiatives have demonstrated a wide variety of ways of addressing one or more of these concerns. 
p. 209. Scaling up community activism: the role of intermediaries in collective approaches to community energy

Research on community energy has tended to focus on the various facets of community (renewable) energy generation (e.g. Walker et al., 2007; Cass et al., 2010) and community approaches to addressing energy efficiency (e.g. Catney et al., 2013; Middlemiss, 2011; Heiskanen et al., 2010). Meanwhile, the holistic outcomes potentially achieved through collective community action on energy is less addressed and harder to quantify (Walker et al., 2007, Parag et al., 2013). These include social and economic benefits such as local ownership and control, and concepts of community cohesion, empowerment, resilience and social wellbeing. The important role of intermediaries is only now starting to emerge, acknowledging how individual community groups can derive significant benefit from the intermediary organisations which support them. Hargreaves et al (2013) have identified the role that intermediary actors' play in connecting and supporting individual projects and Seyfang et al's UKwide survey of community energy noted the value of 'intermediary networks, to ensure community energy projects have the resources they need to progress and achieve their objectives' (Seyfang et al., 2013: 988). Parag et al (2013), in their network approach to community energy, discuss the centrality of intermediary organisations as providing a vital communication channel between communities and (local) government. Intermediaries undertake facilitating, configuring and brokering activity between parties (Stewart and Hyysalo, 2008), are commonly defined by their 'inbetween-ness' (Moss, 2009) and have previously been described as 'bottom-up policy implementers' (Backhaus, 2010).

In this paper we contribute to recent debate on the role of intermediaries in community energy by reflecting on two recent activities in Bristol: a participatory action research project undertaken by local community energy groups working with the University of Bristol to explore the impact of seed funding and role of intermediaries in community energy; and the development and publication of the 'Bristol Community Strategy for Energy' (hereafter called the 'Bristol Strategy') (BEN, 2013). The Bristol Strategy was published six months ahead of the national UK Community Energy Strategy, and a comparison of the two highlights the roles that intermediaries played in the specific setting of Bristol.

\section{Theory, policy and practice of community energy}

\section{Sustainability transitions and intermediaries}

We approach this article through an emerging body of research that explores sustainability transitions (Markard et al., 2012; Smith et al., 2010). Within this body of work, local innovation within communities can be interpreted as 'niches' where the role for community groups is to nurture and develop new ideas and help them to flourish into wider system transformations (Seyfang and Smith, 2007). More broadly, this body of work offers a way of thinking about changes to crucial systems of production and consumption, it contains theories which help us understand complex, large-scale transformations and policy and management prescriptions for fostering niche-based alternatives to existing incumbent systems (Hoogma et al., 2002; Schot and Geels, 2007). The role of intermediary organisations in fostering and supporting experimentation and niche growth has recently received increasing attention and can therefore be a fruitful theoretical lens with which to approach intermediary roles in scaling up community activity.

In a recent study of intermediary activity in UK community energy, Hargreaves et al (2013) suggests existing intermediaries fall into a number of different categories, including: national organisations such as the Centre for Sustainable Energy (CSE) which formed 'in support of the alternative technology movement'; regionally based 
p. 210. Scaling up community activism: the role of intermediaries in collective approaches to community energy

organisations set up in response to government funding for renewables such as the Severn and Wye Energy Agency; independent consultants and professional service providers such as Pure Leapfrog who provide legal and financial support; and looser networks for information exchange and events.

To understand what intermediaries actually do, perhaps one of the clearest ways is to look at existing typologies (table 1). Hargreaves et al (2013), drawing on Geels and Deuten (2006), suggests four key roles for intermediaries in niche development: (1) aggregation of knowledge, as a process of decontextualising knowledge from local projects into more abstract and mobile forms, (2) creation of institutional infrastructure, such as forums and newsletter etc which serve as a repository and circulation of abstract knowledge, (3) coordination and framing, in which collective knowledge starts guiding local projects, and (4) brokering and managing partnerships with external parties. Kivimaa (2014) focuses on intermediary roles in the development of internal niche processes. Under each process, she lists potential roles of intermediaries. Finally, an earlier study by Van Lente and colleagues (2003) addressed intermediaries operating at a systems level and group intermediary roles around three ongoing and key elements of innovation and transformation.

\section{Table 1: Roles of intermediaries in niche development}

\begin{tabular}{|c|c|c|}
\hline $\begin{array}{l}\text { Roles of } \\
\text { intermediaries in } \\
\text { niche development } \\
\text { (Hargreaves et al., } \\
2013 \text { ) }\end{array}$ & $\begin{array}{l}\text { Intermediary roles as contributors } \\
\text { to niche internal processes } \\
\text { (Kivimaa, 2014) }\end{array}$ & $\begin{array}{l}\text { Roles of systemic } \\
\text { intermediaries in transition } \\
\text { processes } \\
\text { (Van Lente et al. 2003) }\end{array}$ \\
\hline $\begin{array}{l}\text { Aggregation of } \\
\text { knowledge from } \\
\text { diverse sources }\end{array}$ & $\begin{array}{l}\text { Articulation of expectations and } \\
\text { visions: } \\
\text { - } \quad \text { Articulation of needs, } \\
\text { expectations and requirements } \\
\text { - Strategy development } \\
\text { - Acceleration of the application } \\
\text { and commercialisation of new } \\
\text { technologies } \\
\text { - Advancement of sustainability } \\
\text { aims }\end{array}$ & $\begin{array}{l}\text { Articulation of options and } \\
\text { demand: } \\
\text { - Demand articulation and } \\
\quad \text { strategy development, }\end{array}$ \\
\hline $\begin{array}{l}\text { Coordination and } \\
\text { framing action } \\
\text { Brokering and } \\
\text { managing } \\
\text { partnerships }\end{array}$ & $\begin{array}{l}\text { Building social networks: } \\
\text { - } \quad \text { Creation and facilitation of new } \\
\text { networks } \\
\text { - Gatekeeping and brokering } \\
\text { - } \quad \text { Configuring and aligning } \\
\text { interests } \\
\text { - Managing financial resources - } \\
\text { finding potential funding and } \\
\text { funding activities } \\
\text { - Identification and management } \\
\text { of human resource needs (skills) }\end{array}$ & $\begin{array}{l}\text { Alignment of actors and } \\
\text { possibilities: } \\
\text { - Identifying, mobilizing and } \\
\text { involving relevant actors } \\
\text { - Organizing discourse, } \\
\text { alignment, consensus } \\
\text { - Management of complex, } \\
\text { long-term innovative } \\
\text { projects }\end{array}$ \\
\hline
\end{tabular}


p. 211. Scaling up community activism: the role of intermediaries in collective approaches to community energy

Learning processes:

- Knowledge gathering, processing, generation and combination

- Technology assessment and evaluation

- Prototyping and piloting

- Investments in new businesses

- Communication and dissemination of knowledge

- Education and training

- Provision of advice and support

- Creating conditions for learning by doing and using

Clearly there is considerable overlap in these lists: they serve to approximate the generic terrain in which we might conceptually situate community activity and the roles of intermediary organisations in support. They will also serve as a reference point to which we will return in later sections to clarify observed actions and deviations from existing theory.

\section{UK energy policy}

'Green' energy policy in the UK has tended to focus on actions by large energy companies and businesses, with targets for emissions, renewable energy generation and demand reduction leaving little space for community-led approaches, and community energy traditionally being viewed as peripheral to achieving national energy policy objectives. However, since the late 1990s, momentum and support has gathered behind community participation in energy. In 2007, Walker and colleagues highlighted the shift in government discourse from a basic understanding that communities should be consulted, to the idea that projects should be led by and for the community (Walker et al., 2007). This trend has continued in the Low Carbon Transition Plan (DECC, 2009) and, most recently in the publication of the national Community Energy Strategy (DECC, 2014). Increasing rhetoric was accompanied by a range of initiatives designed to support, promote or fund community renewable energy and energy efficiency projects. Prominent initiatives included Clear Skies (2003-6), the Low Carbon Communities Challenge (2009-11) and the Local Energy Assessment Fund (LEAF) (2012). These initiatives have provided bursts of funding in a competitive and piecemeal way, resulting in some commentators declaring community energy has grown 'in spite of' rather than 'because of' government policy (Roberts, 2014). Policy has failed however to catch up with the increasingly important role recognized for intermediary organisations with little specific funding or support being made available (Parag et al., 2013).

Launched in January 2014, the national Community Energy Strategy (DECC, 2014) sought to place 'communities at the heart of energy policy' (p.7). The strategy defines community energy as community projects or initiatives engaging in one of four areas: (1) reducing energy use, (2) managing energy better, (3) generating energy and (4) purchasing energy. Alongside the four core areas, partnerships with public, private and third sector organisations are highlighted as key to achieving future objectives, as is monitoring and evaluation of what works. Importantly (and regrettably) their narrow definition of community energy excludes projects and initiatives run by local authorities, 
p. 212. Scaling up community activism: the role of intermediaries in collective approaches to community energy

housing associations and, significantly, intermediary organisations, although they are included as potential partners.

\section{Bristol}

Bristol has a long history of environmental innovation and activism (Brownlee, 2011) and community approaches to energy have been present in the city for a number of years, reflecting the considerable variety in community energy that is discernable nationally. In 2011, 18 initiatives at various stages of development were identified as operating within the city (CSE, 2011). Since then more have formed, although coverage across the city is uneven. At a neighbourhood scale, these initiatives include local transition groups considering energy in the context of climate change and peak oil, and local energy groups focusing on issues such as fuel poverty and energy efficiency and offering advice and support to their communities - in both more and less affluent areas. Other groups operate at a wider city-scale including energy generation co-ops and eco open-home events. Still others are technology or interest based. As elsewhere, groups tend to be set up by a core of dedicated individuals that seek to engage and support the needs of local communities. One of the aims of the Bristol Strategy was to widen participation across the city.

In the Bristol context, two key intermediaries have formed that support community energy. The Centre for Sustainable Energy (CSE) is an established charity supporting individuals and communities in sustainable energy. Although it has a national remit, CSE carries out substantial support work in its hometown of Bristol and surrounding areas. The Bristol Energy Network (BEN) was initiated by and is comprised of local groups and organisations, acting as a forum for bringing together groups to share experiences and knowledge and to develop common solutions. The success of ten groups in securing funding from LEAF at the end of 2011 gave marked impetus to greater consolidation of action in the city and showed the importance of a collective response and the value of supporting organisations in helping groups work together (Bird et al., 2013).

\section{Developing a community's strategy for energy}

\section{Initial research activity and engagement}

'Maintaining Momentum in Bristol Community Energy' was a university-funded research and knowledge exchange project in 2012-13. It involved researchers working alongside BEN and CSE to explore how communities 'maintain momentum' from government seed grants and to examine the roles of existing intermediaries. The project stemmed from the particular success of Bristol energy groups in securing funding from the Government's LEAF grants in 2012. The project was interested in why they had achieved such success and what it would mean for them in the future. Each stage of the project was explored with community participants to shape subsequent activities by the researchers.

Within the project, we analysed the individual end-of-project reports that each LEAF recipient prepared and conducted an online survey asking local groups about their experiences of LEAF, their next steps and what supported or hindered their ambitions. This analysis showed the value placed on intermediaries. CSE had helped many of the groups submit and run their LEAF projects, providing common templates and work packages. This was seen as 'very useful' or 'essential' in eight out of ten cases: a typical survey statement, as provided by one group, was that 'Without CSE work packages, we would have struggled to put together a valid bid and achieve a fraction of 
p. 213. Scaling up community activism: the role of intermediaries in collective approaches to community energy

what we did. Their input was invaluable'. Across all of the LEAF projects, technical support and access to information and other projects was an essential role played by CSE, BEN and other support organisations. BEN was especially valued for its role in bringing groups together to share experiences, thus 'supporting each other' and 'stopping them from acting in isolation' (Bird et al., 2013: 31). It was also recognised that BEN and CSE have a role in engaging with policy makers, feeding back the issues and concerns arising on the ground as local groups respond to new local and national policy initiatives. Other findings which were later to feed into the development of the strategy showed some consistent concerns around general levels of understanding of energy and energy efficiency by the wider public, inadequate access to information and expertise and a need for more core resourcing, both human and financial, to take projects forwards (similar to Seyfang et al's findings in 2013 and CSE, 2011).

In November 2012, the idea of an analogy between community energy and the primary and secondary housing co-ops of the 1970s and 80 s was presented to a BEN meeting. In order to flourish, primary housing co-ops (consisting of tenant members collectively owning and/or managing the housing in which they live) needed the support of secondary co-ops which (were at least partially administered by their primaries and) provided them with a range of promotional, development, training and management services. Secondary support was critical to the success of the primary co-ops and the areas where no support was available have historically had no co-ops (Duncan, 1992). Drawing on this analogy for community energy, the research project team suggested that each community energy group, as a 'primary', rather than owning housing, owns renewable assets or its members' interventions and aspirations to influence energy practices. The intermediary organisations in community energy therefore act like secondary co-ops, providing similar services to their members. One of the priorities emerging from our survey was 'co-ordination of activities' and the housing analogy supported this, placing the role of BEN more clearly and formally as that of an intermediary and suggested what could be done collectively that would achieve more than the sum of the individual actions. The analogy thus encouraged strategic thinking, helping community groups to think about a systemic picture of the sector and the possible outcomes over time of the various structures that could be developed to support them.

Finally, a participatory mapping exercise explored connections between local groups and local and national stakeholders, with around 30 attendees from local community energy groups using mapping templates of local, regional and national stakeholders to draw in the existing connections and how strong they were and to highlight where links were lacking. The mapping revealed some weak but necessary links, particularly to business and government at the local level and to the wider public, but also pointed to the value of intermediaries' connections giving increased access and cooperation with regional and national organisations.

Outputs were discussed with local groups through participation in bi-monthly network open-meetings. The iterative outcomes of these meetings shaped a trajectory which led to the development of the Bristol Strategy, a process in which the university continued to play a participatory, intermediary role. The research thus contributed to the development of the Bristol Strategy, by raising awareness of the notion of intermediary organisations and the possibility of achieving more through collaboration, by developing a better understanding of what was working in Bristol and the barriers, and by bringing an external perspective to a shared vision of what community energy in the city might look like and could deliver in the future. It helped to lift the community energy groups above the day-to-day practicalities and activities with their local communities and into thinking about their needs in the longer term. 
p. 214. Scaling up community activism: the role of intermediaries in collective approaches to community energy

\section{A grassroots strategy for collective action}

'Putting communities at the heart of Bristol's energy system' (BEN, 2013).

The research carried out by the university, together with grassroots knowledge from the BEN team and policy perspectives from the city council, provided a context for shaping how the possibilities of the strategy were presented at the first strategy development workshop. Here, various 'intermediaries' with different perspectives and roles came together to present ideas and facilitate discussions. First, a representative from Community Action Groups, Oxfordshire presented their own experience of strategy development before BEN and CSE volunteers, a council officer and university researchers presented different perspectives and facilitated roundtable discussions. About 50 people representing the broad spectrum of community energy in Bristol participated in the workshop, from which a long list of ideas and wishes coalescing around five core themes were developed. These five themes became the basis of the Bristol Strategy (BEN, 2013) and can be seen at the core of the strategy diagram in figure 1.

Figure 1: The visual depiction of the Bristol Community Strategy for Energy and its vision statement

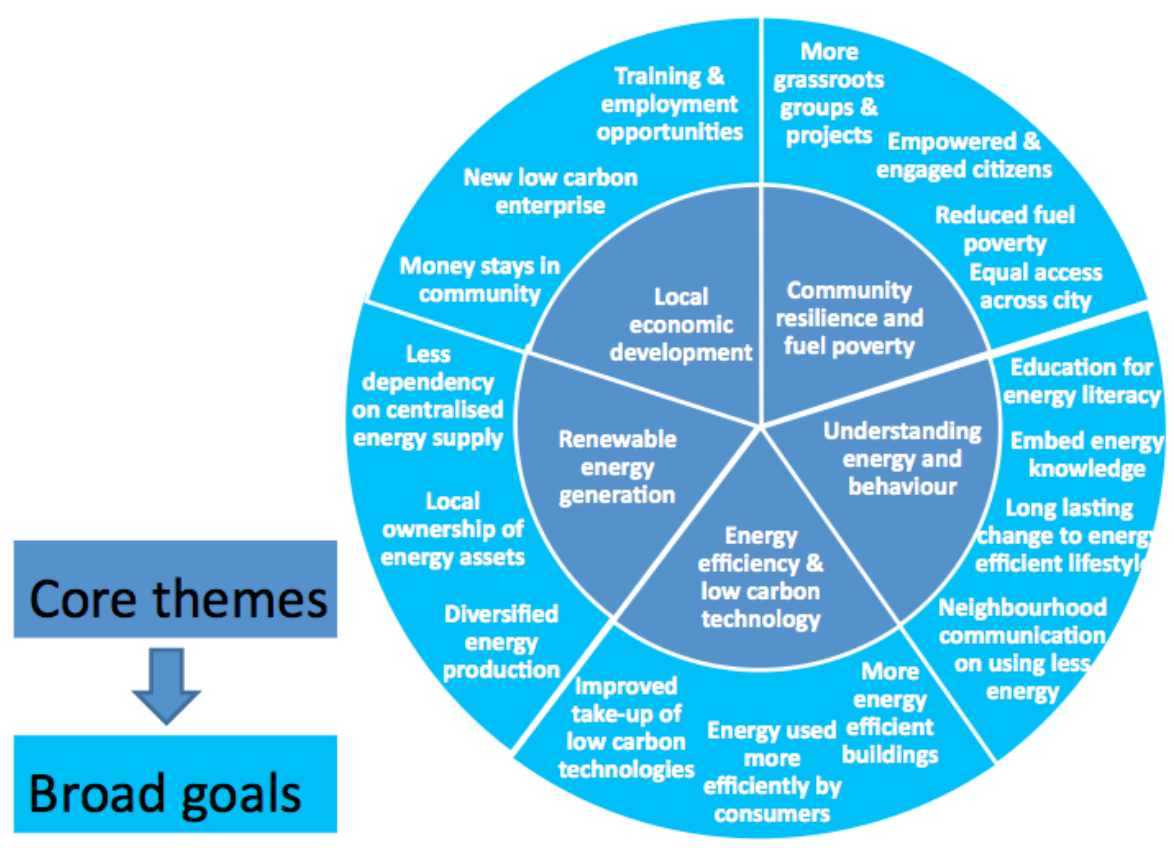

"A city where everyone has access to sufficient affordable low-carbon energy for their needs; where wise and innovative use of energy empowers citizens and enhances the economy, with active communities across the city generating and managing a significant amount of their energy need."

[Reproduced with the permission of BEN CIC directors]

Two further workshops and collaborative writing efforts followed, resulting in a further level of detail being added. The themes build on one another and recognise that community resilience and empowerment underpins subsequent understanding and action. All those involved were very clear that the strategy and community approaches 
p. 215. Scaling up community activism: the role of intermediaries in collective approaches to community energy

to sustainable energy had to have democratic and inclusive core values allowing everyone to play a part and ensuring local benefits. The Strategy additionally recognises that community groups can achieve more by working with the local authority and businesses:

“The Strategy sets out aims and steps for community level action on energy [in Bristol] and seeks to enable local community groups to work in collaboration with local authorities, the private sector and third sector organisations on sustainable energy issues." (BEN, 2013)

As well as the five themes, the strategy recognises some overarching actions as common to all themes: (1) learn from examples elsewhere, incorporate best practice and seek to influence new policy, (2) co-ordination across the city to share learning and scale up activity, and (3) secure new sustainable financing and funding sources. These are activities particularly suited to intermediaries and reflect the roles suggested elsewhere (e.g. Hargreaves et al., 2013).

The earlier research had found that individual groups initially particularly valued BEN as providing a forum for meeting other groups and discussing issues and as a source of information. In looking ahead and increasingly during the strategy process, participants recognised that a 'hub' organisation which could speak collectively for Bristol's community energy interests at a policy level and bring together individual ideas into bigger projects was what was required - reflecting in part what we found in looking at the co-operative housing analogy and also Hargreaves et al's subsequent paper in October 2013. It is also recognised that a support organisation needs to be self-sustaining - again, drawing on the housing analogy, the secondary co-ops lacked an asset base so were dependent on government funding or income from their membership of primaries, without funding they failed and with them the primaries that they sought to support (Alcock and Bird, 2013).

\section{Intermediaries, strategies and scaling up}

Recent research has recognised the key role that intermediaries play in supporting the development of grassroots initiatives by helping them to diffuse, share learning and facilitate dialogue with external organisations. In the context of the Bristol Strategy, we can identify at least five separate actors as undertaking intermediary roles within its short development cycle. CSE, as the established intermediary, played a facilitatory role, providing financial and human resources. Second, BEN was an essential element in the development of a comprehensive and locally relevant community strategy, providing a common platform which local groups and actors felt comfortable and confident in engaging with, and co-ordinating the individual efforts of its membership. Third, the representative from an external intermediary organisation shared experience and learning. Finally, we note how university researchers and the council officer undertook intermediary roles within the process. The latter brought facilitation skills and connections within and from the council. The former brought a different lens to the strategy development both through the primary research and as a 'mediator' (Osborne, 2004), contextualising activity with reference to the national picture and to other sectors and helping in the formation of new ideas and approaches. Through their work, university researchers developed their own originally unanticipated, participatory, intermediary role.

This identification of university researchers and a city council officer as undertaking roles associated with intermediary actors extends Hargreaves and colleagues (2013) categories of intermediaries within community energy in the UK. In this case, key 
p. 216. Scaling up community activism: the role of intermediaries in collective approaches to community energy

intermediation roles were performed or supported by individuals not normally considered as intermediary actors. It extends the possible sources of intermediation and acknowledges that other organisations or individuals may have the capacity or skills to facilitate or configure activity that is useful in scaling up. With this widening of scope in mind, additional sources of intermediation may be emerging from energy companies, such as Good Energy's support for community renewables (Good Energy, 2014) or OVO's offer to community groups of a 'white label' energy company (OVO, 2014; see also Tweed, this issue).

All these actors created a space for the strategy to be formed, coordinated and rationalised. Together, they performed a variety of intermediary roles: they were able to articulate common expectations, establish a common vision, reinforce the creation of a common network, mobilise additional actors and situate individual group activities. In practice, they steered a pragmatic course through the varied ambitions for the strategy, one that was inclusive of a significant variety of community and local voices rather than something centrally orchestrated. The development of a local strategy sets the possibility for coordination and framing of activity in the future (cf. Hargreaves et al., 2013).

The variety of intermediaries identified further suggests a collaborative approach to intermediation, since various skills, expertise and resources were drawn from these different actors. It suggests, at least where strategy formation is concerned, intermediation maybe undertaken by a variety of actors acting in concert. Whilst existing literature tends to emphasise individuals or organisations as intermediaries (e.g. Kivima, 2014), this case reminds us of the different forms that intermediation can take (Van Lente et al., 2003). Furthermore, we might identify the variety of intermediation sources as a strength, providing legitimacy in the process through each actor's existing credibility. Support of the council, university, CSE and BEN created a space in which strategy development was viewed as broad, open and inclusive, as demonstrated by the ability of the process to carry a diversity of actors.

Through the process, BEN has strengthened its legitimacy as a common platform for community energy at the city level, both internally with its members and externally as representing local energy initiatives to other stakeholders. This is important in scaling up activity, for instance where the diversity of small groups and their fragmented volunteer basis makes it hard for larger organisations to engage: an intermediary which spans this diversity is of considerable benefit both to the local groups and the external organisations that might want to work with them.

Referring back to the analogy with co-operative housing in the 1970 s and 80 s and the roles outlined in Table 1, we can compare the roles observed in the various intermediaries considered here, through and beyond strategy development. For example, BEN and CSE help new groups to develop and aggregate knowledge, whilst CSE in particular provides some of the technical support similar to that of the secondary co-ops. CSE and the university play a bridging, articulating and translating role to regulatory structures at a national level with BEN doing this locally, and all intermediaries identified have some role in brokering partnerships and co-ordinating activities. In contrast, a more recent example of community led housing (Moore and Mullins, 2014) sees intermediaries more as formal conduits from government to grassroots, which is favoured by resource holders but removes them from the community-led initiatives that they support. The tension between formalising to meet the demands of funders and strategic partners whilst remaining representative of the variety of grassroots initiatives from whence they came can be an issue for intermediary organisations seeking to secure their future through establishing core resourcing. In the Bristol case, we could argue that the tiers of intermediaries allows 
p. 217. Scaling up community activism: the role of intermediaries in collective approaches to community energy

different degrees of remove from the grassroots groups, strengthening their legitimacy to act in different arenas.

The identification of the council as a source of intermediation is different and complementary to their partnership role depicted in the national strategy. Emphasis on local authorities' resources (physical, human, financial) and structure (local planning), suggests a strategic partner to community energy. It fails however to acknowledge the potentially important role of councils to actively configure and facilitate local action. For the Bristol Strategy, the capacity of the council to support nascent articulation of community demands (for participation in energy systems) was important for widening participation.

Continuing to address the national strategy in comparison, we note some key differences in relation to intermediation and scaling up. First, DECC has taken a diverse area (in community energy) and attempted to define it. The result is a definition that includes community projects and joint ventures but not initiatives run by local authorities, housing associations or intermediary organisations. In contrast the Bristol Strategy, based on cross-sector consultation, celebrates the diversity and innovation of community approaches and the roles of different types of organisations. The broader effect of the former is to close down - rather than the latter's opening up of experimentation and learning-by-doing (Barnes, 2014). The Bristol Strategy recognises community action as only one piece of a new energy policy puzzle. It acknowledges that a new approach is needed, one in which community groups play a major role, 'in collaboration with local authorities, the private sector and third sector' (BEN, 2013: 5). As such, it talks about 'empowered and engaged citizens' as well as community groups. It views communities not as the vanguard but important sources of diversity, empowerment and engagement with contemporary and future energy systems. In contrast, the national strategy backs 'those who choose to pursue community energy' (DECC, 2014: 7) rather than citizen participation per se. Our point here is that rather than simply being pragmatic in engaging with existing interest, there could be greater ambition in seeking to engage ordinary citizens in complex change processes.

Of course there was always an inherent paradox in creating a national strategy for local action. Based at the city-scale, the Bristol Strategy is able to incorporate a wider diversity of voices with fluid boundaries. The presence of diverse intermediation sources encouraged a citywide view and culminated in seeking to support wider engagement and reach beyond the 'usual suspects', for example through 'working with or alongside alternative social, faith and recreational groups' and delivering 'equal access [to community projects] across the city' (BEN, 2013, 6 and 11). The focus on widening participation is apparent in the core of the Bristol Strategy: although energy, in terms of efficiency and generation through renewables, is important, building community, understanding and economic benefits are also central to developing a comprehensive and cohesive movement in which people across the city can participate in and benefit from. The sequence of 'community resilience' leading to 'understanding energy' then 'energy efficiency', 'renewable energy' and 'economic development' draws on a wider systems type approach, lifting it above individual behaviours and actions. Many community groups are run by small groups of volunteers and actions that engage the wider community are vital to them developing understanding and taking action. This is not an issue that features strongly in the national strategy but is presented as key to achieving real change by the Bristol Strategy. 
p. 218. Scaling up community activism: the role of intermediaries in collective approaches to community energy

\section{Conclusion}

Community energy is receiving growing attention from government, practitioners and academics alike, with the increasing maturity of the field being seen nationally and locally in 2014, and with calls for the scaling up of community energy through access to new finance and professional services. To add to this debate, we have reflected on two recent activities in Bristol, a participatory research project and the development of a grassroots community strategy for energy, to consider the role of intermediaries in scaling-up. In doing so, we have drawn attention to the role of intermediary organisations as having been largely overlooked by DECC's national Community Energy Strategy.

Existing theory (e.g. Van Lente et al., 2003) and research on community energy (e.g. Parag et al., 2013) suggests a necessary role for intermediary organisations in supporting groups and sharing learning. Our research builds on this and suggests they also have an important role in representing their local groups at a policy level, developing shared projects, and increasing participation to spread the benefits of community approaches more widely across their local area. Intermediaries do this by representing community energy beyond those already involved, providing a focal point of access for new entrants into community energy and being a conduit through which outside actors can engage. Drawing on analogies with co-operative and community-led housing, intermediary organisations fill essential roles in bridging to policy and supporting grassroots activity, whilst needing to be mindful of maintaining (1) legitimacy as representing their communities and (2) credibility with external bodies.

Discussion of the Bristol Strategy formation notes a greater diversity in the sources of intermediation than has previously been acknowledged, encompassing academic institutions and local authorities as well as organisations more traditionally defined as 'intermediaries' such as CSE and BEN. Councils in particular appear to have a multifaceted role in local and community-scale action, as strategic actors with resources but also capacity to support, align and extend participation. With a wider interpretation of intermediaries in mind it is interesting to consider the entrance of companies like OVO Energy as offering disruptive innovations in partnership with communities.

The national strategy still places community energy narrowly as a peripheral activity concerned with small scale supply and shared action on energy efficiency. It does not take a more open, holistic view of community energy and its potential to transform stagnant energy systems. It sets out in some detail what the government will do to support those community energy groups that want to grow but pays little attention to how to use community approaches to widen engagement. The Bristol Strategy in contrast, sets out more ambitious ideas about how to engage more communities in sustainable energy and bring economic benefits into the local economy by upskilling the supply chain and promoting local businesses. It puts people first and encourages innovation and inclusion. It does this by recognising the multiplicity of relevant actors at all levels and supports involvement by all. The presence of multiple intermediaries in developing Bristol's local strategy was key in helping it to move beyond those already involved. Through this wider engagement, community energy can really address the potential for scaling up, bringing in a range of actors not just in partnerships as suggested by the national strategy but in direct support of local groups.

Our recommendation for a future revision of the national strategy would be to widen the definition of community energy to support greater experimentation and learning, to recognise the role of intermediaries and finally, to approach community activity as a means to increase engagement and participation in contemporary and future changes to the energy system. Energy needs to undergo a significant transformation over the 
p. 219. Scaling up community activism: the role of intermediaries in collective approaches to community energy

next decade if we are to meet carbon reduction targets and community energy has the potential to play a significant role if communities are engaged more widely in the idea of a new energy future.

\section{Acknowledgements}

Professors Morag McDermont and Bronwen Morgan of the University of Bristol for initiating and overseeing the Maintaining Momentum project and commenting on the various drafts of this paper, Rupert Alcock for carrying out the initial housing co-op research, the University of Bristol for funding the project through its 'Enterprise and Impact Development Fund' and BEN and CSE for being collaborative and receptive.

* Correspondence address: Caroline Bird, Faculty of Social Sciences and Law, University of Bristol, 1 Priory Road, BS8 1RJ, UK. Email: caroline.bird@bristol.ac.uk

\section{References}

Alcock, R and Bird, C. (2012) Maintaining Momentum in Bristol Community Energy. Lessons from the history of the housing co-operative movement. Bristol: University of Bristol. Available at: http://www.bris.ac.uk/medialibrary/sites/law/migrated/documents/interimreport1.pdf [accessed 31 October 2014]

Backhaus, J. (2010) Intermediaries as Innovating Actors in the Transition to a Sustainable Energy System. Central European Journal of Public Policy, 4, 1, 86108.

Barnes, J. (2014) Bristol's vision of a new energy system [Online] 18 th Mar. Available at http://newstartmag.co.uk/your-blogs/bristols-vision-of-a-new-energy-system/ [accessed 19 November 2014]

Bird, C., Alcock, R., Morgan, B., McDermont, M. (2013) Maintaining Momentum in Bristol Community Energy, Project report, June 2013. Bristol: University of Bristol. Available at: http://www.bris.ac.uk/medialibrary/sites/law/documents/Maintaining\%20Momentum\%20project\%20report\% 20June\%202013.pdf [accessed 27 November 2014]

Brownlee, E. (2011) Bristol's Green Roots. Bristol: Schumacher Institute.

Bristol Energy Network (2013) Bristol Community Strategy for Energy. Bristol: BEN. Available online at http://www.bristolenergynetwork.org/strategy

Cass, N., Walker, G. and Devine-Wright, P. (2010) Good Neighbours, Public Relations and Bribes: The politics and Perceptions of Community Benefit Provision in Renewable Energy Development in the UK. Journal of Environmental Policy and Planning, 12, 3, 255-275.

Catney, P., Dobson, A., Hall, S., Hards, S., MacGregor, S., Robinson, Z., Ormerod, M. and Ross, S. (2013) Community Knowledge Networks: an action-oriented approach to energy research. Local Environment: the International Journal of Justice and Sustainability, 18, 4, 506-520.

CSE (2011) Supporting Bristol's Community Energy Initiatives : Projects and priorities July 2011. Report produced by the Centre for Sustainable Energy, Bristol, for Bristol City Council, funded by the Department of Energy and Climate Change.

DECC (2009) The UK Low Carbon Transition Plan. Change. Department of Energy and Climate Change. London: The Stationery Office.

DECC (2014) Community Energy Strategy: Full Report. London: Department of Energy and Climate Change. 
p. 220. Scaling up community activism: the role of intermediaries in collective approaches to community energy

Duncan, P. (1992) Co-Operative Housing: beyond customer care to consumer control. Coventry: Institute of Housing.

Geels, F., and Deuten, J.J. (2006) Local and global dynamics in technological development: a socio-cognitive perspective on knowledge flows and lessons from reinforced concrete. Science and Public Policy, 33, 4, 265-275.

Good Energy (2014) 'The truth about the UK's community energy potential' [Online] $16^{\text {th }}$ Apr. Available at www.goodenergy.co.uk [accessed 21 November 2014]

Hargreaves, T., Hielscher, S., Seyfang, G. and Smith, A. (2013) Grassroots innovations in community energy: The role of intermediaries in niche development. Global Environmental Change, 23, 868-880.

Heiskanen, E., Johnson, M., Robinson, S., Vadovics, E. and Saastamoinen, M. (2010) Low Carbon Communities as a context for individual behavioural change. Energy Policy, 38, 7586-7595.

Hoogma, R., Kemp, R., Schot, J., and Truffer, B. (2002). Experimenting for Sustainable Transport. London, UK: Spon Press.

Kivimaa, P. (2014) Government-affiliated intermediary organisations as actors in system-level transitions. Research Policy, 43, 8, 1370-1380.

Markard, J., Raven, R. and Truffer, B. (2012) Sustainability transitions: An emerging field of research and its prospects. Research Policy, 41, 6, 955-967.

Middlemiss, L. (2011) The effects of community-based action for sustainability on participants' lifestyles. Local Environment: The International Journal of Justice and Sustainability, 16, 3, 265-280.

Moss, T. (2009) Intermediaries and the governance of sociotechnical networks in transition. Environment and Planning A, 41, 6, 1480-1495.

Moore, T and Mullins, D (2014) Scaling-up or going viral? Comparing self-help housing and community land trust facilitation. Voluntary Sector Review, 4, 3, 333-353.

Osborne, T. (2004) On mediators: intellectuals and the ideas trade in the knowledge society. Economy and Society, 33, 4, 430-447.

OVO Energy (2014) OVO communities. Available at: https://www.ovoenergy .com/energy-plans/communities/ [accessed 25 November 2014]

Parag, Y., Hamilton, J., White, V. and Hogan, B. (2013) Network approach for local and community governance of energy: The case of Oxfordshire. Energy Policy, 62, 1064-1077.

Roberts, S (2014) 'DECC's Community Energy Strategy. Is this when we shift from 'in spite of' to 'because of'? Sort of.' Available at http://www.cse.org.uk/news/view/1801 [Accessed 01 November 2014]

Schot, J. and Geels, F.W. (2008) Strategic niche management and sustainable innovation journeys: theory, findings, research agenda, and policy. Technology Analysis \& Strategic Management, 20, 5, 537-554.

Seyfang, G., Park, J. and Smith, A. (2013) 'A thousand flowers blooming? An examination of community energy in the UK'. Energy Policy, 61, 977-989.

Seyfang, G. and Smith, A. (2007) Grassroots Innovations for Sustainable Development : Towards a New Research and Policy Agenda. Environmental Politics, 16, 4, 584 603.

Smith, A., Voß, J. and Grin, J. (2010) Innovation studies and sustainability transitions : The allure of the multi-level perspective and its challenges. Research Policy, 39, $435-448$.

Stewart, J. and Hyysalo, S. (2008) Intermediaries, Users and Social Learning in Technological Innovation. International Journal of Innovation Management, 12, 03, 295-325.

Urry, J. (2014) The Problem of Energy. Theory, Culture \& Society, 31, 5, 3-20.

Van Lente, H., Hekkert, M., Smits, R. and Waveren, B. A. S. Van. (2003) Roles of systemic intermediaries in transition processes. International Journal of Innovation Management, 7, 3, 247-279. 
p. 221. Scaling up community activism: the role of intermediaries in collective approaches to community energy

Walker, G., Hunter, S., Devine-Wright, P. and Evans, B. (2007) Harnessing community energies: Explaining and evaluating community-based localism in renewable energy policy in the UK. Global Environmental Politics, 7, 2, 64-82. 